\title{
A qualitative study exploring perspectives towards rational use of medicines in Pakistan's Malaria Control Program (MCP)
}

\author{
Madeeha Malik ${ }^{1, *}$, Mohamed Azmi Hassali ${ }^{1}$, Asrul Akmal Shafie ${ }^{1}$, Azhar Hussain ${ }^{1,2}$ \\ ${ }^{1}$ Discipline of Social and Administrative Pharmacy, School of Pharmaceutical Sciences, Universiti Sains Malaysia, Malaysia, \\ ${ }^{2}$ Hamdard Institute of Pharmaceutical Sciences, Hamdard University, Pakistan
}

\begin{abstract}
Malaria is one of the most important global public health problems threatening the health of the population owing to prevailing socio-economic conditions and epidemiological reasons in Pakistan. This qualitative study has focused on the perspectives held towards the rational use of medicine intervention among malaria control program officials. Eight semi-structured interviews with all officials working for the malaria control program in Islamabad were conducted. The interviews, which were audio-taped and transcribed verbatim, were evaluated by thematic content analysis and by all authors. All respondents agreed on successful implementation of the malaria control program in Pakistan for controlling malaria by improving diagnostic and treatment facilities and promoting rational case management through training of prescribers. However, funding is still the major challenge faced by the program for its future implementation.
\end{abstract}

Uniterms: Malaria. Malaria Control Program. Drug/rational use. Intervention. Pakistan.

\begin{abstract}
A malária é um dos mais importantes problemas sanitários globais, que ameaça a saúde população devido às condições socioeconômicas e por razões epidemiológicas no Paquistão. Este estudo qualitativo focouse nas perspectivas no sentido do uso racional da intervenção médica entre os funcionários do programa de controle da malária. Oito entrevistas semiestruturas com todos os funcionários que trabalham no programa de controle da malária foram conduzidas em Islamabad. As entrevistas, que eram gravadas e transcritas, foram avaliadas por análise temática do conteúdo e por todos os autores. Todos os respondentes concordaram com o êxito da implementação do programa de controle da malária no Paquistão por meio do aprimoramento do diagnóstico e de facilidades do tratamento, promovendo a gestão racional por meio do treinamento dos prescritores. Entretanto, o financiamento é, ainda, o principal desafio enfrentado para a implementação futura do programa.
\end{abstract}

Unitermos: Malária. Programa de controle da malária. Fármaco/uso racional. Intervenção. Paquistão.

\section{INTRODUCTION}

Malaria is one of the most importantlargest global public health problems and imposes a major burden on health in developing countries. Half of the world's population is at risk of malaria with an estimated 250 million clinical cases and nearly one million deaths reported in 2006. This makes it the leading cause of morbidity and mortality globally, especially in pregnant women and children (Murtaza et al., 2009). Around five

*Correspondence: M. Malik. Discipline of Social and Administrative Pharmacy, School of Pharmaceutical Sciences, Universiti Sains Malaysia, 11800 - Minden - Penang, Malaysia. E-mail: mady_sweet1@yahoo.com million confirmed cases of malaria are reported each year from countries outside Africa, of which almost three million are from India and Pakistan. However, it is generally assumed that the actual number of cases in the world is much greater. Many victims of malaria do not have access to diagnostic and treatment facilities; therefore, the prevalence of the disease is not always recorded and only a small number of cases are officially reported globally each year (WHO, 2005).

New approaches have been developed for malaria case management, for selective vector control and for epidemic detection. Effective medicines and preventive measures are available (UNICEF, 2000). Higher treatment coverage with well-equipped health services and safe 
and effective antimalarial drugs need to be available and accessible to the whole population. However, these effective and relatively inexpensive interventions reach only a small proportion of the populations in need, mainly due to insufficient financial resources (Kouyate et al., 2007). To resolve this dilemma, malaria has been integrated into national health programs and partnerships have been increased both internationally and nationally by the Roll Back Malaria (RBM), an initiative by the World Health Organization (WHO), which has led to increased global awareness of malaria (Nigeria, 2010).

Over the years, malaria eradication or control has been the goal of many developing countries. Nearly 90 countries have a national malaria control program (MCP) to combat malaria. The Global Fund is one of the biggest international donors and currently contributes two thirds of all international finance for malaria, supporting 175 malaria-specific programs in 83 countries (WHO, 2009). It was created in 2002 to dramatically attract, manage and disburse resources to the areas of greatest need. It does not directly implement programs, but instead relies on a broad network of partners with national MCPs within the affected countries to strengthen their health systems by financing these programs and supplying local knowledge and technical assistance (Malaria Policy Center, 2010).

The national MCPs vary from country to country, and depend on the malaria statistics and current needs of the country. As malaria morbidity and mortality continue to increase in most countries, the international agencies and MCPs have strenghthened undividual programs by utilising available resources, developing quality control strategies, effective program decision making and continuous program evaluation for improving the efficiency and effectiveness of these programs (Bryce et al., 1994). An integrated MCP was developed and implemented in Ghana in 2006 and was successful in the control of malaria in this country. Ongoing surveillance, monitoring, research and partnership with the relevant authorities and with local communities were considered factors responsible for the success of the program (USAID, 2011). Another successful program (PAL + ) for malaria control by the French ministry was launched in 1999 and focused on developing methods of prevention and treatment of malaria and other communicable diseases for countries in Sub-Saharan Africa, Southeast Asia and Latin America (Agid, 2004). The national MCP of Zambia was also successful in reducing the rate of deaths due to malaria (Malaria Control Program, 2009). On the other hand, many MCPs have failed to accomplish what they initially planned. Problems evident in the success of these projects have involved logistic and financial constraints and poor project program management. An example of such a failure is the national MCP of Burkina Faso which was not successfully implemented due to lack of funds (Kouyate et al., 2007).

Pakistan is among 109 countries with endemic malaria with an estimated 1.5 million annual malaria episodes (Murtaza et al., 2009). It is a major health problem, threatening the health of the people due to prevailing socio-economic conditions and the epidemiological situation (Malik et al., 2011). A MCP was initiated in Pakistan in the 1950s and has passed through several evolutionary phases. In 1975, a malaria control strategy was adopted with provincial commitment to implementation and in 1998, Pakistan joined the global Roll Back Malaria (RBM) initiative (Kakar et al., 2010). The present study was designed to explore the role of the $\mathrm{MCP}$, major outstanding challenges faced in promoting rational drug use, achievements, and the future prospective of the program for advancing resource mobilisation and collaborative partnerships.

\section{METHODS}

\section{Design and setting}

The study was approved by a panel of experts at the MCP, Ministry of Health, Government of Pakistan. Because little research has been undertaken in Pakistan to explore the perspectives held towards the rational use of medicine intervention among MCP officials, qualitative research was adopted to explore the issue. The study was conducted at the MCP in Islamabad, which is controlled by the Ministry of Health, Government of Pakistan. The program operates through its Federal Directorate, Provincial Health Departments, EDO Health Officers and Microscopists at tertiary, secondary and primary healthcare levels in the country. The program is mainly funded by the Government of Pakistan and also receives 22 million Us Dollars of global funding, annually. The program has implemented interventions for the control of malaria in nineteen districts from different provinces of Pakistan by involving international non-governmental organisations (NGOs), for example Mercy Corps, and the National Rural Support Program (NRSP).

\section{Participants}

Eight interviews with all of the officials working at the MCP in Islamabad were conducted. The officials were recruited through personal contacts. The identified participants were contacted in person or by telephone to 
arrange interview appointments. Written consent was obtained from all participants prior to the interview.

\section{Study tool}

A semi-structured interview guide was used as a study tool. The interview guide was developed after extensive literature review. A number of aspects to be addressed were already identified from the literature and this ensured that the key issues regarding the role of the MCP were covered with all respondents. While creating the questions, the focus was to keep the questions as open as possible to give interviewees a maximum opportunity to express their views. The first draft of the interview guide was discussed among the authors and was modified after a few rounds of discussion. The pre-testing of the guide was conducted with four MCP officials to check whether particular questions were useful in the retrieval of information. Specific probes were identified during the pilot interviews and the interview guide was subsequently modified.

\section{Procedure and interview process}

The interviews were conducted from April to May 2011 at the offices of the respondents. The interviews mainly focused on the perceptions of MCP officials on current scenarios of rational drug use in cases of malaria, major challenges in promoting rational drug use in malaria, drug management, current achievements of the program and its future prospective. Probing questions were used where necessary and participants were given freedom to express their views at the end of the interview session. Each interview lasted approximately 20 to 30 minutes at a time convenient for the respondents. All interviews were conducted in the local language. Permission for recording was obtained and all interviews were recorded.
Each interview was transcribed verbatim. Transcribed interviews were subjected to thematic content analysis, and the transcripts were analysed for relevant content to identify the emerging categories (Malik et al., 2011).

\section{RESULTS}

The interviews with officials focused on three major components, i.e. working and outreach of the program, strategies and major challenges faced for promoting rational drug use in malaria control, and achievements and the future prospective of the program. Thematic content analysis of these components yielded additional major themes and sub-themes. The demographics of the MCP officials are given in Table I.

\section{THEMES}

\section{Theme 1: Outreach and major partners of the MCP}

The MCP has mainly targeted 19 districts in different provinces, where they are working with the collaborative efforts of the Government of Pakistan and the Global Fund as stated by all the officials.

"The outreach of the program is in 19 districts in different provinces. Our major partners are the Global Fund and the Government of Pakistan. We are working in coordination with government officers to promote capacity building of the professionals". (MCP.O 3)

"Basically we are targeting 19 districts of Pakistan in different provinces. Our major partners are the Global Fund and the Government of Pakistan. We have six subrecipients, basically international NGOs who are also working as our major partners in the implementation of the program". (MCP.O 6)

TABLE I - Demographic characteristics of officials working in the MCP, Pakistan

\begin{tabular}{lllll}
\hline Code & Gender & Qualification & Experience & Current designation \\
\hline MCP.O 1 & Male & MBBS/MPH & 4 years & WHO coordinator \\
MCP.O 2 & Female & MBBS/MPH & 2 years & Monitoring and evaluation officer \\
MCP.O 3 & Female & MBBS/MPH & 4 years & Project officer \\
MCP.O 4 & Male & Masters in social sciences & 1 year & Monitoring and evaluation officer \\
MCP.O 5 & Male & MBBS & 2 years & Monitoring and evaluation officer \\
MCP.O 6 & Male & Masters in Pharmacy & 4 years & Procurement and supply manager \\
MCP.O 7 & Male & B-pharmacy/LLB/DPH & 2 years & Human resources and logistics manager \\
MCP.O 8 & Male & MBA Management & 2 years & Finance and accounts manager \\
\hline
\end{tabular}

$\mathrm{MCP} . \mathrm{O}=$ malaria control program official 


\section{Theme 2: Provision of facilities by the program}

Diagnostic kits, free medicines, nets, trained staff and rational case management were seen as the major facilities provided by the officials.

"We provide diagnostic kits and nets for vulnerable groups like pregnant women and children under five. Beside this we provide training to the doctors and ensure availability of free of cost drugs at these facilities. We identify centres which are functional and have staff. Then we train the doctors at these centres according to WHO guidelines. We also ensure the training of a microscopist for proper diagnosis at these facilities so that we can get accurate data from these facilities. We have designed a proper information system, get data on a daily basis through emails from all these facilities and update the system regularly". (MCP.O 3)

"According to a study of 2006, it has been reported that there were about 1.6 million suspected cases of malaria in Pakistan out of which confirmed cases were only around 300,000, but according to the pharmaceutical sales figures of 2006 it has been seen that around seventy million doses of antimalarial drugs had been sold which was unjustified. Chloroquine and any antimalarial drugs can easily be purchased from the market for the treatment of malaria without confirmation. We don't have enough microscopist centres and results were available after 24 hours. Therefore we improved the diagnostic facilities and functioning of microscopic centres. Previously, one microscopist centre was available for every 44,000 people but now we have attained a target of 43,000. We have also introduced rapid diagnostic kits through which malaria is confirmed in 20 minutes". (MCP.O 4)

\section{Theme 3: Major contributing factors in irrational drug use in treatment of malaria in Pakistan}

In view of most of the officials' inappropriate diagnoses, antimalarial resistance, lack of trained staff and inappropriate drug management are the major factors promoting irrational drug use in the treatment of malaria in Pakistan.

"Irrational prescribing is common and resistance is the major problem seen while treating malaria. Chloroquine and other antimalarial drugs are being prescribed so frequently to the patients without confirmation that they are usually ineffective when used by the patients who are actually suffering from malaria". (MCP.O 2)

\footnotetext{
"Lack of diagnostic facilities, improper diagnosis
}

and lack of trained microscopists are the major reasons for irrational practice in cases of malaria. Lack of training of doctors is another issue which needs to be addressed. Treatment should be given to confirmed cases of malaria only". (MCP.O 4)

"I think the major factors contributing towards irrational drug use in the treatment of malaria are improper formularies, a flawed procurement process, quantification and forecasting of antimalarial drugs without any proper methodology, inappropriate storage conditions and distribution mechanisms, unethical prescribing practices, a large number of quacks and unavailability of antimalarial drugs especially in rural areas". (MCP.O 6)

\section{Theme 4: Role of the health care system in promoting rational drug use in the treatment of malaria in Pakistan}

Most of the officials were of the view that the health care system has failed to play a positive role in promoting rational drug use in the treatment of malaria in Pakistan.

"I don't think that the health care system is playing any significant role in the treatment of malaria. The government spending of the total expenditure on health care is so small that even the tertiary care hospitals don't have sufficient funds, so how can one expect that the funds will be tripled down to the basic health units and dispensaries? Major antimalarial drugs stockouts are seen. The health care system should promote cost effective treatment as not everybody has the capacity to buy medicines". (MCP.O 1)

"I have not heard of any promotion strategy and achievements regarding rational drug use in cases of malaria by the health care system in Pakistan. I have always come across irrational prescribing practices of antimalarial drugs". (MCP.O 2)

"I don't think the health care system has directly contributed any vital role in the promotion of rational drug use in the treatment of malaria". (MCP.O 8)

\section{Theme 5: Role of the MCP in promoting rational drug use in Pakistan}

Appropriate diagnosis, treatment, implementation of standard malaria treatment guidelines and appropriate management of antimalarial drugs were seen as the key roles by most of the officials.

Appropriate diagnosis and treatment

"Our strategy is based on proper diagnosis 
and treatment. There are defined procedures of case management on the basis of which health care providers are being trained and then treat accordingly. In this way, rational drug use is ensured such that only WHO recommended medicines are being used". (MCP.O 5)

"Early diagnosis and then treatment of the positive cases is the focus of our strategy for promoting rational drug use in the treatment of malaria". (MCP.O 7)

Development and training of standard treatment guidelines of malaria

"Training of standard treatment guidelines, known as "case management training", is conducted. Desk guides and manuals are provided. One doctor at every facility is trained for three days and later they train their staff. There are certain places in Baluchistan and Sind where there are no doctors, so shorter training of one or two days is provided to the care providers at these facilities, who are usually female health workers or dispensers". (MCP.O 1)

"A strategic plan of malaria has been made which is being revised after every five years. The strategic plan includes the intention that standard treatment guidelines for malaria will be implemented which will control rational drug use”. (MCP.O 4)

Appropriate drug management of antimalarials

"There are special guidelines of the Global Fund which indicate that all antimalarial drugs and all prequalified suppliers should be WHO certified. In the case of antimalarial drugs, the procurement is usually based on the morbidity method and the annual parasite index is calculated. $30 \%$ extra stock is procured compared to the total district load of malaria cases. Usage is reviewed quarterly through the malaria information system which indicates the number of drugs consumed in a particular month in a specific facility. Drugs are then transferred to the facility with a higher load. This system ensures drug availability and monitors drug stockouts at health facilities. Buffered stocks are kept at a regional level for emergency needs. That is how rational procurement of antimalarial drugs has been ensured". (MCP.O 4)

"A procurement plan is made which focuses on estimation of antimalarial drugs on the basis of case loads and statistics. The availability of antimalarial drugs in the malaria peak season is ensured. Stockouts are regularly monitored and the inter-district distribution of antimalarial drugs is carried out on the basis of malaria load. In time, procurement is the strategy of our program to promote rational drug use". (MCP.O 5)

\section{Theme 6: Major challenges faced by MCP in promotion of rational drug use}

Most of the officials consider funding constraints, irregular monitoring and patient compliance as the major challenges faced in promoting rational drug use in malaria.

"We can make sure that patient has taken the first dose of the antimalarial drug but cannot ensure adherence of the patient to the rest of the therapy, like dots in tuberculosis. Secondly, microscopy which is considered as gold standard in appropriate diagnosis can only be relied upon if the microscopist is supervised regularly. Although we train microscopists, it is difficult to monitor whether they are performing the tests appropriately or not". (MCP.O 1)

"Due to vast distances between health facilities in Baluchistan, it is not possible for EDOs to frequently monitor these settings. Lack of funds is another major challenge faced by the program". (MCP.O 5)

\section{Theme 7: Effectiveness of strategy by MCP}

In view of most of the officials' identification and registration of more malaria cases, training of doctors, positive feedback from the public, continued funding from the donors and verification of dispensing of antimalarial drugs only to confirmed cases are seen as indicators which confirm the effectiveness of the strategy.

"This is, for the first time in the history that, after two years the MCP in Pakistan has been evaluated, and approved for funding of phase II by the Global Fund. Beside this, we received positive feedback from the public. As diagnostic facilities have been improved, more cases are being diagnosed and documented. The confirmation of dispensing of antimalarial drugs to confirmed malaria cases only shows that the strategy has been effective". (MCP.O 5)

"I think by training of prescribers and the provision of artemisinin combination therapy only to confirmed malaria patients, we have been successful in achieving rational drug use in the targeted districts". (MCP.O 3)

\section{Theme 8: Major achievements of the program}

Most of the officials consider training, rational drug use, a low number of cases of resistance and effective treatment of confirmed cases of malaria as the major achievements of the program.

"In the first year, 40,000 positive cases of malaria were effectively treated". (MCP.O 2)

"Only confirmed cases of malaria are treated by 
the trained staff. I think we have ensured rational drug use through training of doctors in standard treatment guidelines and we perceive this as the major achievement of the program". (MCP.O 3)

"I think promotion of combined artemisinin therapy has been effective, as no case of resistance has been reported and the sale of antimalarial drugs has been reduced according to pharmaceutical reports which is a major achievement of the program".(MCP.O 4)

\section{Theme 9: Monitoring of the program}

A monitoring plan and a review of the sale of antimalarial drugs are seen as the best tools for monitoring of the program by the officials.

"The antimalarial drugs procured and distributed are the same throughout the region. Drug specification, source, quality and supplier are the same which is in itself a check". (MCP.O 1)

"A monitoring plan has been designed and monitoring officers regularly supervise the status of rational drug use. The numbers of confirmed malaria cases are verified with the consumption of antimalarials which gives a clear idea about deviation from rational drug use. We will improve day by day". (MCP.O 6)

\section{Theme 10: Future prospective of the program}

Public awareness, proper coordination with the health care system and extensive coverage of the program are seen as the future prospective by officials.

"Proper coordination between the public and private sectors in the next five years will be ensured. We have involved the private sector, due to which more cases are being diagnosed. In this way more coverage will focus on identification of more malaria positive cases". (MCP.O 3)

"In the past, we were more concerned about getting things functional. However, in future we will focus more on quality assurance and public awareness through training which will definitely increase the capacity of the MCP at both central and provincial level in Pakistan". (MCP.O 8)

\section{DISCUSSION}

Malaria is one of the largest public health challenges still faced by health managers in Pakistan. A MCP was established in Pakistan in 1961. The respondents revealed that the major partners of the program are the Global Fund and the Government of Pakistan who work together to promote capacity building of professionals involved in the treatment and control of malaria in this country. The MCP of Pakistan has successfully completed phase I of the malaria proposal and the Global Fund has approved donation for phase II. The activities mentioned in the work plan are being implemented through a public-private partnership model which includes the Government of Pakistan, international NGOs and the WHO. A similar collaborative model for successful implementation of the national MCP in Bangladesh has been reported (Malaria Control Program, 2010).

The officials of MCPs have stated that the number and functionality of diagnostic centres has been improved through the provision of rapid diagnostic kits and training of microscopists. Provisions of free of cost treatment to only confirmed malaria cases and an impregnated net for pregnant women and children under five have also been provided. Similar facilities have been provided by the national MCP in Uganda (2010).

Irrational use of drugs in the health care system remains a major challenge to be addressed. The problem of present irrational practices in the treatment of malaria in the health care system is contributing to the development of resistance, ineffective treatment and economic burden to both patients and society (Olliaro, 2005). Irrational prescribing, resistance to antimalarial drugs and inappropriate diagnosis were highlighted by the respondents as the major factors contributing to irrational drug use in malaria. Resistance to the standard recommended antimalarial drugs is being witnessed, including artemether in Pakistan (Khatoon et al., 2009). High prevalence of in vivo resistance to chloroquine has been reported, although no high grade resistance to sulphadoxine-pyrimethamine by $\mathrm{P}$. falciparum in southern Pakistan has been found (Ghanchi et al., 2011). Falciparum malaria accounts for $18 \%$ to $62 \%$ of all cases of malaria in different regions of Pakistan with resistance to one or more antimalarial drugs reaching up to $40 \%$ at present. Several studies conducted in Pakistan have reported a more prevalent resistance of falciparum malaria to chloroquine; the use of artimisinin derivatives is more effective but too costly for a developing country to be used on large scale (Shah et al., 1997, Rana, 2004 \#257, Fox et al., 1985, Ejaz et al., 2007). Similar patterns of irrational drug use have been reported in Ghana and Cambodia (Chareonkul et al., 2002; Abuakua et al., 2005).

Rational use of drugs at health centres remains a problem in Pakistan. Despite improvements through different interventions in pharmaceutical selection, procurement, distribution, and financing, the problem of rational drug use still persists. It is often observed that prescribing and dispensing practices are not up to the mark 
in public and private sector health facilities of developing countries including Pakistan (Nizamani et al., 2006). Most medical practitioners in developing countries including Pakistan are inclined to practice their own protocols to treat malaria rather than adhering to standard regimens which in turn promotes irrational drug use and leads to the emergence of higher rates of resistance to antimalarial drugs (WHO, 2002). Most of the respondents considered the design and implementation of national treatment guidelines for malaria through training of the prescribers as the best tool to address these issues contributing to irrational drug use in malaria.

One way to promote rational use is to ensure that all essential antimalarial drugs are available on a regular basis (Mannan et al., 2009). The MCP officials claimed that the availability of antimalarial drugs at health facilities has been ensured through the malaria information system which indicates the number of drugs consumed in a particular month at a specific health facility.

The respondents were of the view that the MCP has been able to control malaria to a considerable extent in the targeted districts and no case of drug resistance has been reported, which is seen as the major achievement of the program. These improvements are due to better diagnostic and treatment facilities. A similar strategy of improved diagnostic facilities and treatment adopted by the national MCP has been successful in reducing the number of malaria cases in Iran (Raeisi et al., 2009).

\section{CONCLUSION}

The MCP in Pakistan has targeted high endemic areas which focus on the 19 districts of the country. All respondents agreed on successful implementation of the MCP in Pakistan in controlling malaria by improving diagnostic and treatment facilities and promotion of rational case management through training of prescribers. Free of cost treatment only to confirmed malaria cases and impregnated nets for pregnant women and children under five have also been provided. Although the MCP of Pakistan has been successful in achieving its target and has been eligible for funding of the second phase, the funds from international donors are still under competitive pressure. There is no assurance that international donors are a sustainable source of finance. The failure of national MCPs in several developing countries due to lack of funds for their implementation has been a common reason. In spite of the challenges ahead, the Government of Pakistan, private sector stakeholders and development partners have to unite their efforts and work together to expand the national MCP and achieve the national millennium development goals.

\section{ACKNOWLEDGMENTS}

We acknowledge all of the officials of the MCP of Pakistan for their cooperation, especially Mr Naveed Choudary and Mr Sardar Shabbir.

\section{REFERENCES}

ABUAKUA, B.K.; KORAMA, K.A.; BINKAB, F.N. Antimalarial prescribing practices: a challenge to malaria control in Ghana. Med. Princ. Pract., v.14, p.332-337, 2005.

AGID, F. The PAL + program, an incentive concerted action about malaria and associated infectious diseases, for developing countries. J. Soc. Biol., v.198, p.207-211, 2004.

BRYCE, J.; ROUNGOU, J.B.; DINH, P.N.; NAIMOLI, J.F.; BREMAN, J.G. Evaluation of national malaria control programmes in Africa. Bull. World Health Org., v.72, p.371-381, 1994.

CHAREONKUL, C.; KHUN, V.L.; BOONSHUYAR, C. Rational drug use in Cambodia: study of three plot health centers in Kampong Thom province. Southeast Asian J. Trop. Med. Public. Health, v.2, p.418-424, 2002.

EJAZ, A.; HAQNAWAZ, K.; HUSSAIN, Z.; BUTT, R.; AWAN, Z.I.; BUX, H. Treatment of uncomplicated plasmodium falciparum malaria with quinine-doxycycline combination therapy. JPMA. J. Pak. Med. Assoc., v.57, p. 502.

FOX, É.; SARWAR, M.; KHALIQ, A.A.; STRICKLAND, G.T. 1985. Chloroquine-resistant Plasmodium falciparum: now in Pakistani Punjab. Lancet, v.325, p.1432-1435.

GHANCHI, N.K.; URSING, J.; BEG, M.A.; VEIGA, M.I.; JAFRI, S.; MÅRTENSSON, A. 2011. Prevalence of resistance associated polymorphisms in Plasmodium falciparum field isolates from southern Pakistan. Malar. J., v.10, p.18-23.

KAKAR, Q.; KHAN, M.A.; BILE, K.M. Malaria control in Pakistan: new tools at hand but challenging epidemiological realities. East. Mediterr. Health J., v.16, p.S54-S60, 2010.

KHATOON, L.; BALIRAINE, F.N.; BONIZZONI, M.; MALIK, S.A.; YAN, G. 2009. Prevalence of antimalarial drug resistance mutations in Plasmodium vivax and $\mathrm{P}$. falciparum from a malaria-endemic area of Pakistan. Am. J. Trop. Med. Hyg., v.81, p.525-528. 
KOUYATE, B.; SIE, A.; YE, M.; ALLEGRI, M.D.; MULLER, $O$. The great failure of malaria control in Africa: a district perspective from Burkina Faso. Plos Med., v.4, p.997-1000, 2007.

MALARIA CONTROL PROGRAM. Zambia National Malaria Control Centre Monitoring and Evaluation Newsletter. 2009. Available at: http://www.nmcc.org.zm/files/NMCCME-newsletter_dec_09.pdf Accessed on: 5 July 2011.

MALARIA CONTROL PROGRAM. NMCP in Bangladesh. Government of people's republic of Bangladesh. 2010. Available at: http://www.nmcp.info/index. php?option $=$ com_content $\&$ view $=$ article $\&$ id $=8 \&$ Itemid $=1$ 1 Accessed on: 9 july 2011.

MALARIA POLICY CENTER. Program and Funding Organizations in the Fight against Malaria. Washington, 2010. (A project of Malaria no more). Available at: http:// www.malariapolicycenter.org/malaria_academy/finance mechanisms Accessed on: 9 july 2011.

MALIK, M.; HASSALI, M.A.; SHAFIE, A.A.; HUSSAIN, A. Strategic solution to malaria eradication in pakistan. $J$. Pharm. Pract. Res., v.41, p.73, 2011.

MANNAN, A.A.; MALIK, E.M.; ALI, K.M. Antimalarial prescribing and dispensing practices in health centres of Khartoum state. East. Mediterr. Health J., v.15, p.122-128, 2009.

MURTAZA, G.; MEMON, I.A.; MEMON, A.R.; LAL, M.; KALLAR, N.A. Malaria morbidity in Sindh and the plasmodium species distribution. Pakistan J. Med. Sci., v.25, p.646-649, 2009.

MURTAZA, G.; MEMON, I.A.; MEMON, A.R.; LAL, M.; KALLAR, N.A. Malaria morbidity in sindh and the plasmodium species distribution. Pakistan J. Med. Sci., v.25, p.646-49, 2009.

NIGERIA. Federal Ministry of Health. National Malaria Control Programme. A road map for RBM impact in Nigeria: a 5-years Strategic Plan: 2006-2010. Abuja, 2010. Available at: < http://www.rbm.who.int/countryaction/nsp/nigeria. pdf $>$ Accessed on: 10 september 2010.

NIZAMANI, A.; KALAR, N.A.; KHUSHK, I.A. Burden of malaria in Sindh, Pakistan: a two years surveillance report. J. Liaqat Uni. Med. Health Sci., v.5, p.76-83, 2006.
OLLIARO, P. Drug Resistance Hampers Our Capacity to Roll Back Malaria. Clin. Infect. Dis., v.41, p.247-257, 2005.

RAEISI, A.; NIKPOOR, F.; RANJBAR, K.M.; FARAJI, L. The trend of malaria in I.R. Iran from 2002 to 2007. Hakim Res. J., v.12, p.35-41, 2009.

SHAH, I.; ROWLAND, M.; MEHMOOD, P.; MUJAHID, C.; RAZIQUE, F.; HEWITT, S. DURRANI, N. 1997. Chloroquine resistance in Pakistan and the upsurge of falciparum malaria in Pakistani and Afghan refugee populations. Ann. Trop. Med. Parasit., v.91, p.591-602.

UGANDA. Ministry of health. Malaria control programme. Uganda malaria control strategy plan: 2005/06 - 2009/10. Available at: <http://www.rbm.who.int/countryaction/nsp/ uganda.pdf $>$ Accessed on: 15 nov. 2010.

UNICEF. Promoting Rational Use of Drugs and Correct Case Management in Basic Health Services. UNICEFs Programme Division, 2000. Available at: http://www.unicef. org/prescriber/eng_p18.pdf Accessed on: 11 dec. 2010.

USAID. Malaria Operational Plan - FY 2011 (Year 4). Ghana: Presidents malaria initative program. 2011. Available at: <www.pmi.gov/countries/mops/fy11/ghana_mop-fy11> Accessed on: 12 sept. 2010.

WORLD HEALTH ORGANIZATION. Intercountry workshop on monitoring therapeuitc efficacy of anti malarial drugs. 2002. Available at: www.emro.who.int/rbm/news-yem02. htm Accessed on: 22 Apr. 2010.

WORLD HEALTH ORGANIZATION. Malaria Control Today. Geneva: Roll Back Malaria Department, 2005. Available at: http://www.who.int/malaria/publications/atoz/mct workingpaper/en/index.html. Accessed on: 15 nov. 2009.

WORLD HEALTH ORGANIZATION. From Prevention to Treatment: The Global Fund's Comprehensive Approach to Fighting Malaria. Geneva: Roll Back Malaria Partnership, 2009.

Received for publication on $14^{\text {th }}$ November 2011 Accepted for publication on $03^{\text {rd }}$ November 2012 